\title{
Adölesanlarda Öz-bakım Gücü - Sağlığı Geliştirme Arasındaki îlişki ve Öz-bakım Gücünü Etkileyen Faktörler $\infty$
}

\author{
Nuriye YILDIRIM ȘiȘMAN ${ }^{1}$, Gülnur ARSLAN ÇAKIR ${ }^{2}$
}

öz

Amaç: Adölesanların öz-bakım gücü - sağı̆ğı geliştirme davranışları arasındaki ilişkiyi ve özbakım gücünü etkileyen faktörleri incelemektir.

Gereç ve Yöntem: Çalışma tanımlayıcı ilişki arayıcı bir araştırmadır. Şubat Aralık 2017 tarihleri arasında Düzce ili merkez sınırları içerinde bulunan ve devlet okulu olan bir Anadolu Lisesinde 9,10 ve 11. sınıfta okuyan 453 öğrenci ile yapılmıştır. Araştırma verileri Öğrenci Bilgi Formu, Öz-Bakım Gücü Ölçeği ve Adölesan Sağlığı Geliştirme Ölçeği ile toplanmıştır.

Bulgular: Çalışmada, adölesanların öz-bakım gücü toplam puanı $83.85 \pm 16.55$ ve sağlığı geliştirme puan ortalaması $131.75 \pm 24.19$ bulunmuştur. Adölesanlar sağlığı geliştirme ölçeğinin kendini gerçekleştirme alt boyutundan en yüksek puanı alırken (28.69 \pm 6.43), en düşük puanı egzersiz alt boyutundan almışlardır (15.26 \pm 4.64). Öz-bakım gücü ile adölesan sağlığı geliştirme ölçeği puan ortalamaları arasında orta düzeyde pozitif yönde istatistiksel olarak anlamlı bir ilişki bulunmaktadır ( $p<0.01, r: 0.649)$. Öz-bakım gücünü açıklayan değişkenlerin; kendini geliştirme, sağlık sorumluluğu, sağlık algısı, stres yönetimi, beslenme ve cinsiyet olduğu bulunmuştur.

Sonuç: Adölesanların öz-bakım gücü ve sağlığı geliştirme puan ortalamaları orta düzeydedir. Adölesanlar sağlığı geliştirme ölçeğinin kendini gerçekleştirme alt boyutundan en yüksek puanı alırken, en düşük puanı egzersiz alt boyutundan almışlardır.

Anahtar kelimeler: Adölesan, sağlığın geliştirilmesi, öz-bakım

\begin{abstract}
The Relationship Between Self-Care Agency and Health Promotion in Adolescents and Factors Affecting Self-Care Agency

Aim: This study aims to identify the relationship between self-care agency and health promotion behaviors of adolescents and factors affecting their self-care agency.

Material and Methods: This descriptive and correlational study was conducted with 453 students in the 9th, 10th, and 11th grades in a public Anatolian high school located in Duzce city center between February and December 2017. The data were collected using a Student Information Form, the Self-Care Agency Scale, and the Adolescent Health Promotion Scale.

Results: In the study, the total self-care agency score of the adolescents was $83.85 \pm 16.55$, and their health promotion score average was $131.75 \pm 24.19$. While the adolescents got the highest score from the self-realization subscale of the health promotion scale $(28.69 \pm 6.43)$, they received the lowest score from the exercise subscale $(15.26 \pm 4.64)$. There is a moderately positive and statistically significant relationship between self-care agency and adolescent health promotion scale mean scores ( $p<0.01, r$ : 0.649 ). The variables that explain self-care agency were self-realization, health responsibility, perception of health, stress management, nutrition, and gender.

Conclusion: The adolescents' self-agency and health promotion mean scores were at the medium level. The adolescents obtained the highest mean score on the self-realization subscale and the lowest mean score on the exercise subscale.

Keywords: Adolescent, health promotion, self-care
\end{abstract}

1Dr. Öğr. Üyesi, Düzce Üniversitesi Sağlık Bilimleri Fakültesi Hemşirelik Bölümü, Halk Sağlığı Hemşireliği Anabilim Dalı, Düzce, Türkiye, E-mail: nuriye3@gmail.com , nuriyeyildirim@duzce.edu.tr, İş: +90 3805421141 - 3510 GSM: 053250266 50, ORCID: 0000-0003-3745-3751

${ }^{2}$ Hemşire, Okmeydanı Eğitim ve Araştırma Hastanesi Çocuk Yoğun Bakım Servisi, Şişli, İstanbul, Türkiye, e-mail: G__arslan81@ @otmail.com,Tel: (0212) 314 55 55,ORCıD: 0000-0002-6484-5446

Geliş Tarihi: 05 Aralık 2019, Kabul Tarihi: 06 Kasım 2020

Atıf/Citation: Yıldırım Şişman N, Arslan Çakır G. Adölesanlarda Öz-bakım Gücü - Sağlığı Geliştirme Arasındaki İlişki ve Öz-bakım Gücünü Etkileyen Faktörler. Hacettepe Üniversitesi Hemşirelik Fakültesi Dergisi 2021;8(1):29-34. DOI: 10.31125/hunhemsire.906938 


\section{GiRiş}

Dünya nüfusunun altıda biri adölesanlardan oluşmaktadır ${ }^{1}$. Adölesan dönemde, fizyolojik, hormonal ve psikoseksüel yönlerden pek çok değişim yaşanmaktadır². Adölesan dönemdeki sağlık alışkanlıkları, adölesanların sadece mevcut sağlıklarını değil, aynı zamanda yetişkin döneminde sağlıklarını ve hatta epigenetik etkiyoluyla gelecekteki çocuklarının sağlığını tehlikeye atabilmektedir ${ }^{1}$. Bu bağlamda adölesan dönemi pek çok riski barındırması nedeni ile insanın yaşam döngüsünde kilit bir gelişim dönemi olarak karşımıza çıkmaktadır ${ }^{3}$.

Öz-bakım gücü, hem kendine bakma yeteneğini hem de optimal sağlığı sağlamak, sürdürmek ya da geliştirmek için gerekli olan faaliyetleri yerine getirmeyi içerir ${ }^{4}$. Öz-bakım gücü sağlıklı kişiler tarafından gerçekleştirilen günlük sağlık davranışlarına atıfta bulunmak için de kullanılır ${ }^{5}$. Kendi kendine bakım davranışları, kişinin hayatta kalmasını sağlamaktan kendini gerçekleştirmeye kadar uzanan çeşitli görevleri yerine getirmesine katkıda bulunur 6 . Öz-bakım gücü sağlıklı ve hasta bireylerin günlük yaşamlarının bir parçasıdır. Fiziksel ve ruhsal sağlığı sürdürmeyi, sosyal ihtiyaçları karşılamayı, hastalıkları ve kazaları önlemeyi amaçlayan tüm uygulamaları içerir ${ }^{7}$. Özellikle sağlıklı ve aktif yaşlanma için öz-bakım gücü uygulamalarının yaşamın erken dönemlerinde benimsenmesi de önemlidir ${ }^{8}$. Orem'in Öz Bakım Gücü Teorisine göre; bireylerin evrensel ve gelişim öz bakım gereksinimlerinin karşılanması, birinci basamak sağık hizmetlerinin sunumunda hastalıkların önlenmesi ve sağlığın geliştirilmesinin önemli bir bileşenidir ${ }^{9}$.

Pender'in sağlığı geliştirme modelinin amacı, sağlıklı yaşam biçiminin oluşturulmasıdır ${ }^{10}$. Sağlıklı yaşam biçimi davranışları, bireylerin sağlık durumlarını korumak, geliştirmek ve hastalıktan korunmak için uyguladığı davranışların bütünüdür ${ }^{11}$. Sağlıklı yaşam biçimi davranışları, optimal sağ ık, kişisel tatmin ve üretken yaşam gibi pozitif bir sağlık sonucuna ulaşmayı hedefler ${ }^{12}$. Pender'in sağlığı geliştirme modeli ile, bireyin özgeçmişi ve kendisine yönelik algısı ele alınarak bütüncül bir yaklaşım oluşturulur. Adölesan sağlığının geliştirilmesi için sağlık sorunları ve riskli davranışlar konusunda adölesanların bilgilendirilmesi, danışmanlık yapılması, sağlıklı yaşam biçiminin, güvenli ve destekleyici çevrenin oluşturulması önemlidir ${ }^{2}$

Adölesan dönemdeki riskli sağlık davranışlarının yaygınlığı, yetişkinlik dönemindeki kronik hastalıklar ve yaşam kalitesi ile olan ilişkileri göz önüne alındığında adölesanların riskli sağlık davranışları bir halk sağlığı önceliği olarak ele alınmalıdır ${ }^{13}$. Adölesanların günlük yaşamlarını geçirdikleri aile ortamında ve okullarda sağlıklarının geliştirilmesi ve koruyucu faktörlere odaklanılması gerekmektedir ${ }^{3}$. Okullar sağlığı koruma ve geliştirme becerilerinin kazandırıldığı yerlerdir ${ }^{14}$. Afro-Amerikan gençlerle yapılan nitel bir çalışma da aile ve okul deneyimlerinin, çocukluk dönemindeki sağlığı etkilediği, çocukluk ve aile deneyimlerinin de gençlik dönemindeki sağlığı etkilediği belirlenmiştir ${ }^{15}$. Adolesanların düzenli izlemleri yapılarak biyopsikososyal gelişimlerinin takip edilmesi, sağlık riski taşıyan tutum ve davranışlarının belirlenerek koruyucu önlemlerin alınması, kapsamlı ve bütüncül sağlık bakımının verilmesi adölesan dönemin sağlıklı geçirilmesi açısından önemlidir ${ }^{16}$. Birinci basamakta çalışan sağ ık çalışanları bu araştırmadan elde edilen verileri, adölesanların öz-bakım gücü ve sağlığını geliştiren müdahaleleri yönlendirmede kullanabilirler. Adölesanların öz-bakım gücünü ve sağlığı geliştirme davranışlarını değerlendirmek, öz-bakım gücünü ve sağlığı geliştiren hemşirelik müdahalelerini planlamak için önerilir.

\section{Araştırmanın Amacı}

Bu çalışmanın amacı, adölesanların öz-bakım gücü ve sağlığı geliştirme davranışları arasındaki ilişkiyi ve özbakım gücünü etkileyen faktörleri incelemektir. Araştırma soruları: 1. Adölesanların öz-bakım gücü ve sağlığı geliştirme düzeyleri nedir?

2. Adölesanların öz-bakım gücü ve sağlığı geliştirme düzeyleri arasında ilişki var mıdır?

3. Bağımsız değişkenlerin öz-bakım gücü üzerine etkisi nedir?

\section{GEREÇ ve YÖNTEM}

\section{Araştırmanın Türü}

$\mathrm{Bu}$ çalışma tanımlayıcı ilişki arayıcı bir araştırmadır. Bu araştırma Şubat 2017- Aralık 2017 tarihleri arasında Düzce ili merkez sınırları içerinde bulunan bir devlet okulu olan Anadolu Lisesinde yapılmıştır. Lisenin 700 öğrencisi, 50 öğretmeni bulunmaktadır. II merkezine yakın bir konumdadır.

\section{Araştırma Evren ve Örneklemi}

Çalışmanın evrenini, 2016-2017 Eğitim Öğretim yılında Düzce il merkezinde bulunan ve devlet okulu olan bir Anadolu lisesinde 9,10,11. sınıfta okuyan 547 öğrenci oluşturmuştur. Araştırmaya katılmaya gönüllü olan 453 (evrenin \%83,0'ı) öğrenci örneklemi oluşturmuştur.

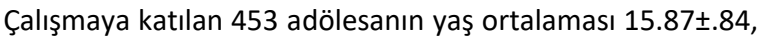
\%61.1'i kadın, \%35.8'i 11.sınıfta okumakta, \%51.2'si sosyal aktivitelere katılmakta, \%52.3'ü sağığını çok iyi olarak algılamaktadır.

\section{Veri Toplama Araçları}

Araştırma verileri öğrenci Bilgi Formu, Öz-Bakım Gücü Ölçeği ve Adölesan Sağlığı Geliştirme Ölçeği ile toplanmıştır.

\section{Öğrenci Bilgi Formu}

Öğrenci Bilgi Formu araştırmacılar tarafından literatüre göre hazırlanmıştır4,6,17-19. Bu bilgi formunda; araştırma kapsamına alınan öğrencilerin cinsiyeti, yaşı, ailenin sürekli yaşadığı yer, annenin ve babanın yaşı, annenin ve babanın eğitim durumu, annenin ve babanın mesleği gibi 19 soruya yer verilmiştir.

\section{Öz-Bakım Gücü Ölçeği}

Araştırmada kullanılan Öz-Bakım Gücü Ölçeği; Kearney ve Fleischer tarafından 1979 yılında geliştirilmişs ${ }^{20}$ ve Nahcivan $(1994)^{21}$ tarafından Türkçe'ye uyarlanmıştır. Ölçek 35 maddeden oluşmaktadır ve bireylerin öz-bakım uygulamaları ile ilgilenme durumlarını ortaya koymaktadır. Ölçekten alınan maksimum puan 140'dır. Ölçekten alınan puanın yüksekliği bireyin öz-bakım ya da kendi kendine bakma gücünün yüksekliğini gösterir. Ölçek için Cronbach 
Alfa güvenilirlik katsayı değeri $0.92^{\prime} \mathrm{dir}^{21}$. Bu çalışma için Cronbach Alfa güvenilirlik katsayı değeri 0.91 bulunmuştur. Adölesan Sağlığı Geliştirme Ölçeği

Adölesan Sağlığı Geliştirme Ölçeği; Chen ve ark. (2003) 22 tarafından geliştirilmiş, Temel ve ark. (2012) ${ }^{23}$ tarafından Türkçe'ye uyarlanmıştır. Ölçek 40 madde ve 6 alt ölçekten oluşmaktadır. Alt ölçekler beslenme, kişiler arası destek, sağlık sorumluluğu, kendini gerçekleştirme, egzersiz, stres yönetimi olarak sıralanmaktadır. Ölçekten alınabilecek en düşük ve en yüksek puanlar 40 ile 200 arasında değişmektedir. Elde edilen puanın yüksek olması sağlığı geliştirme davranışlarının olumlu yönde olduğunu göstermektedir. Ölçek için Cronbach Alfa güvenilirlik katsayı değeri $0.86^{\prime}$ dır $^{23}$. Bu çalışma için Cronbach Alfa güvenilirlik katsayı değeri 0.79 bulunmuştur.

\section{Verilerin Analizi}

Çalışma verileri IBM SPSS Statistics 22 programında çalışımıştır. Verilerin değerlendirilmesinde ortalama, standart sapma, yüzde. min. - max., Pearson korelasyon, bağımsız örneklem t testi, varyans analizi (farklılığa neden olan grubun belirlenmesinde Tukey testi) ve çoklu doğrusal regresyon analizi kullanımıştır. Çoklu regresyon analizi için uç değerler kontrol edilmiştir. Cinsiyet, sağlık algısı, hastalık durumu, sınıf ve sosyal aktivitelere katılımı içeren Kategorik değişkenler dummy (kukla) değişkene dönüştürülerek analiz yapılmıştır. Tüm bağımsız değişkenler modele alınarak enter metodu kullanılmıştır. İstatistiksel anlamlılık düzeyi olarak $p<0.05$ alınmıştır.

\section{Araştırmanın Etik Boyutu}

Araştırmanın yürütülebilmesi için bir Düzce Üniversitesi Etik Kurulundan (2017/16) ve Düzce İ Milli Eğitim Müdürlüğü'nden izin alınmıştır. Okul yönetimi ve öğretmeler ile işbirliği içinde çalışılmıştır. Araştırmaya katılacak adölesanların 18 yaşından küçük olmaları nedeni ile velilerine çalışmanın amacı, yöntemi ve araştırmanın gönüllülük esasına dayandığı hakkında yazılı bilgi öğrenciler ile eve gönderilerek, öğrencilerin velilerinden gerekli izin yazılı olarak alınmıştır. Velilerinden yazılı aydınlatılmış onam alınan ve çalışmaya katılmaya gönüllü olan öğrencilere okul yönetiminin uygun gördüğü ders saatlerinde veri toplama araçları uygulanmıştır.

\section{Araştırmanın Sınırlılıkları}

Araştırmadan elde edilen bulgular çalışmanın yapıldığ Anadolu Lisesinde 2016-2017 öğretim döneminde öğrenim gören öğrencilere genellenebilir.

\section{BULGULAR}

Adölesanların öz-bakım gücü toplam puanı $83.85 \pm 16.55$ ve sağlığı geliştirme puan ortalaması 131.75 \pm 24.19 bulunmuştur. Adölesanlar sağlığı geliştirme ölçeğinin kendini gerçekleştirme $(28.69 \pm 6.43)$ alt boyutundan en

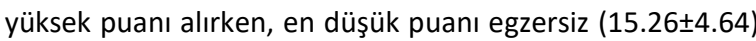
alt boyutundan almışlardır (Tablo 1 ).

Öz-bakım gücü ile adölesan sağlığı geliştirme ölçeği puan ortalamaları arasında orta düzeyde pozitif yönde istatistiksel olarak anlamlı bir ilişki bulunmaktadır ( $p<0.01, r: 0.649$ ) (Tablo 2).
Bu çalışmada, lise öğrencilerinin öz-bakım gücü ile adölesan sağlığı geliştirme alt ölçekleri ve diğer bağımsız değişkenler ile arasındaki ilişki incelenmiştir. Tüm bağımsız değişkenlerin öz-bakım gücü üzerine etkisi çoklu doğrusal regresyon analizi ile değerlendirilmiştir. Öz-bakım gücü bağımlı değişkenindeki değişimin \% 47.9'u bağımsız değişkenler tarafından açıklanmıştır. Oluşturulan model istatistiksel olarak anlamlı bulunmuştur $(\mathrm{F}=36.787 ; \mathrm{p}<0.005)$. Standardize edilmiş regresyon katsayısına (Beta) göre; kendini geliştirme, sağlık sorumluluğu, sağlık algısı, stres yönetimi, beslenme ve cinsiyet öz-bakım gücünün göreli olarak en güçlü açıklayıcıları olarak ortaya çıkmıştır (Tablo 3).

Tablo 1. Kullanılan Ölçek Toplam ve Alt boyut Toplam Puan Ortalamaları $(n=453)$

\begin{tabular}{|l|l|l|l|}
\hline Ölçekler & $\mathrm{X}^{*} \pm$ SD** & $\begin{array}{l}\text { Min***- } \\
\text { Maks**** }\end{array}$ & $\%$ \\
\hline $\begin{array}{l}\text { Öz-Bakım Gücü } \\
\text { Toplam Puan }\end{array}$ & $\mathbf{8 3 . 8 5} \pm \mathbf{1 6 . 5 5}$ & $21-124$ & 67 \\
\hline $\begin{array}{l}\text { Adölesan Sağlığı } \\
\text { Geliştirme } \\
\text { Toplam Puan }\end{array}$ & $131.75 \pm 24.19$ & $57-200$ & 66 \\
\hline $\begin{array}{l}\text { Beslenme alt } \\
\text { boyutu }\end{array}$ & $18.57 \pm 4.77$ & $6-30$ & 63 \\
\hline $\begin{array}{l}\text { Kişiler arası } \\
\text { destek alt boyutu }\end{array}$ & $24.44 \pm 6.04$ & $7-35$ & 71 \\
\hline $\begin{array}{l}\text { Sağlık } \\
\text { sorumluluğu alt } \\
\text { boyutu }\end{array}$ & $24.81 \pm 5.94$ & $8-40$ & 63 \\
\hline $\begin{array}{l}\text { Kendini } \\
\text { gerçekleştirme alt } \\
\text { boyutu }\end{array}$ & $28.69 \pm 6.43$ & $8-40$ & 60 \\
\hline $\begin{array}{l}\text { Egzersiz alt } \\
\text { boyutu }\end{array}$ & $15.26 \pm 4.64$ & $5-25$ & 67 \\
\hline $\begin{array}{l}\text { Stres yönetimi } \\
\text { alt boyutu }\end{array}$ & $19.98 \pm 4.92$ & $6-30$ & 73 \\
\hline * Ortalama, **SD=Standart Sapma, ***Min=Minumum, **** Maks=Maksimum \\
\hline
\end{tabular}

Tablo 2. Adölesanların Öz-Bakım Gücü ve Adölesan Sağlığı Geliştirme ile Arasındaki ilişki ( $n=453$ )

\begin{tabular}{|l|l|}
\hline Ölçek Puan Ortalamaları & Öz-Bakım Gücü \\
\hline Adölesan Sağlığı Geliştirme Ölçeği & $\mathrm{r}=.649^{*} \mathrm{p}=.000$ \\
\hline${ }^{*} \mathrm{p}<0.01$ &
\end{tabular}

$* p<0.01$

Tablo 3. Çoklu Regresyon: Bağımsız Değişkenlerin Öz-Bakım Gücü Üzerine Etkisi

\begin{tabular}{|c|c|c|c|c|c|c|}
\hline & \multicolumn{2}{|c|}{$\begin{array}{l}\text { Standardize } \\
\text { Olmamış Katsayılar }\end{array}$} & \multirow{2}{*}{$\begin{array}{l}\text { Standart } \\
\text { Katsayı } \\
\text { Beta }\end{array}$} & \multirow[b]{2}{*}{$t$} & \multirow[b]{2}{*}{ p } & \multirow[b]{2}{*}{ VIF } \\
\hline & B & $\begin{array}{l}\text { Standart } \\
\text { Hata }\end{array}$ & & & & \\
\hline (Sabit) & 22.604 & 3.439 & & 6.572 & .000 & \\
\hline Beslenme & .455 & .153 & .131 & 2.966 & .003 & 1.652 \\
\hline $\begin{array}{l}\text { Kişiler arası } \\
\text { destek }\end{array}$ & -.040 & .122 & -.015 & -.327 & .744 & 1.671 \\
\hline $\begin{array}{l}\text { Sağlık } \\
\text { sorumluluğu }\end{array}$ & .501 & .133 & .180 & 3.777 & .000 & 1.918 \\
\hline $\begin{array}{l}\text { Kendini } \\
\text { gerçekleştirme }\end{array}$ & .925 & .137 & .360 & 6.743 & .000 & 2.408 \\
\hline Egzersiz & .012 & .153 & .003 & .081 & .936 & 1.568 \\
\hline $\begin{array}{l}\text { Stres } \\
\text { yönetimi }\end{array}$ & .464 & .163 & .138 & 2.852 & .005 & 1.977 \\
\hline Cinsiyet (kadın) & 3.057 & 1.299 & .090 & 2.353 & .019 & 1.240 \\
\hline $\begin{array}{l}\text { Sağlık algısı } \\
\text { (çok iyi) }\end{array}$ & 4.409 & 1.240 & .133 & 3.556 & .000 & 1.186 \\
\hline $\begin{array}{l}\text { Hastalık durumu } \\
\text { (Olan) }\end{array}$ & -.756 & 1.469 & -.019 & -.515 & .607 & 1.115 \\
\hline Sinıf (9.sınıf) & 1.699 & 1.268 & .047 & 1.340 & .181 & 1.022 \\
\hline $\begin{array}{l}\text { Sosyal aktivite } \\
\text { (Katılan) }\end{array}$ & 1.615 & 1.229 & .049 & 1.314 & .190 & 1.167 \\
\hline
\end{tabular}




\section{TARTIŞMA}

$\mathrm{Bu}$ bölümde adölesanların sağlık durumunu etkileyen özbakım gücü ve sağlığı geliştirme davranışları arasındaki ilişki ve özbakım gücünü etkileyen faktörler tartışılmıştır. Çalışmada adölesanların öz-bakım gücü (83.85£16.55) ölçeğinden aldıkları toplam puanın orta düzeyde olduğu belirlenmiştir (Tablo 1). Ergün ve ark. (2009) yaptıkları çalışmada 14-19 yaş grubu adölesanların öz-bakım gücü toplam puan ortalaması $91.33 \pm 15.34$ bulunmuştur ${ }^{24}$. Tüfekçi ve Arıkan (2002) çalışmasında öz-bakım gücü toplam puan ortalaması $89.9 \pm 19.9$ bulunmuştur ${ }^{25}$. Kore' de yapılan bir çalışmada özbakım gücü puanı $158.10 \pm 26.62$ bulunmuş ve daha önce yapılan çalışmalara göre yüksek bulunmuştur ${ }^{26}$. Adölesan dönemdeki sağlık risklerinin azaltılabilmesi için ev ve okullarda adölesanların öz-bakım güçlerinin artırılmasına yönelik müdahalelerin oluşturulması gereklidir.

Çalışmada adölesanların sağlığı geliştirme (131.75 \pm 24.19$)$ ölçeklerinden aldıkları toplam puanın orta düzeyde olduğu belirlenmiştir (Tablo 1). Benzer şekilde Türkiye'de yapılan çalışmalarda da lise öğrencilerinin sağlığı geliştirme toplam puan ortalamaları orta düzeyde $(118,4 \pm 20,0$ - 126.9 \pm 28.7$)$ bulunmuştur ${ }^{17-19,27-29}$. Kore'de yapılan bir çalışmada sağlığı geliştirme puanı $145.67 \pm 35.10$ bulunmuş ve daha önce yapılan çalışmalara göre yüksek bulunmuştur ${ }^{26}$. Adölesan sağlığının korunması ve geliştirilebilmesi için ev ve okullarda adölesanların sağlıklı yaşam biçimi davranışlarının artırılmasına yönelik müdahalelerin oluşturulması gereklidir.

Bu çalışmanın sonucuna göre adölesanlar sağlığı geliştirme ölçeğinden en yüksek puanı kendini gerçekleştirme alt boyutundan almıştır (Tablo 1). Türkiye'de adölesanlar ile yapılan çalışmalarda da benzer sonuçlar elde edilmiştir ${ }^{17,28,30}$. Adölesanlar kendini gerçekleştirme yolunda sağlıklarını koruyup, geliştirmek için yaşam boyu öğrenmeye ihtiyaç duyarlar. Bu bağlamda kendini gerçekleştirme alt boyutundan en yüksek puanı almaları yetişkinlik döneminde de sağlıklarını korumaları ve geliştirmeleri için olumlu bir bulgu olarak karşımıza çıkmaktadır. En düşük puan egzersiz alt boyutundan alınmıştır (Tablo 1). Dağdeviren ve Şimşek (2013)'in çalışmasında da benzer sonuç elde edilmiştir ${ }^{28}$. Diğer bazı çalışmalarda da adölesanlar fiziksel aktivite ve sağlık sorumluluğu alt boyutlarından düşük puan almıştır ${ }^{17,19}$. Kenya'daki kentsel ortamdaki gençlerin televizyon seyretmesi (spor oyunları veya film izlemeleri vb.), cep telefonlarının kullanımı özellikle de teknoloji ve sosyal medyanın kullanımı gibi hareketsiz faaliyetleri içeren sedanter yaşam tarzlarının olduğu ifade edilmektedir ${ }^{31}$. Benzer şekilde Brezilya'daki çoğu adölesanın ekran aktivitelerinde harcadıkları zamanın artmasıyla (2 ila 4 saat) fazla kilonun ve fiziksel hareketsizliğin prevalansında artış eğilimi gözlenmiştir ${ }^{32}$. Sedanter yaşam tarzının getirdiği fiziksel hareketsizlik kilo artışı ve obezite sorununu da gündeme getirmektedir.

Öz-bakım gücü ile adölesan sağlığı geliştirme ölçeği toplam puanı arasında pozitif yönde orta düzeyde ilişki bulunmuştur (Tablo 2). Kore'de hemşirelik kolej öğrencileri ile yapılan çalışmada öz-bakım gücü ve sağlığın geliştirilmesi davranışı arasında zayıf düzeyde anlamlı bir korelasyon olduğu bulunmuştur $(r=0.39, p<0.001)^{26}$. Öz bakım gücü, hem kendine bakma yeteneğini hem de optimal sağlığı sağlamak, sürdürmek ya da geliştirmek için gerekli olan faaliyetleri yerine getirmeyi içerir. Çoğunlukla yaşam biçimi içinde kullanılır ${ }^{4}$ Bu bağlamda araştırma bulgusunda da görüldüğü gibi öz-bakım gücünün artırılması sağlıklı yaşam biçimini destekleyerek sağlığın geliştirilmesini de beraberinde getirecektir.

Regresyon modeline göre; öğrencilerin öz-bakım gücünü en güçlü açıklayan değişkenler göreli olarak kendini gerçekleştirme, sağlık sorumluluğu, sağlık algısı, stres yönetimi, beslenme ve cinsiyettir (\% 47.9) (Tablo 3). Çelik ve Owen (2017) tarafından yapılan bir çalışmada iyilik halinin \%68'ni en güçlü açıklayan değişkenler; beslenme, kendini gerçekleştirme ve kişilerarası ilişkiler olarak bulunmuştur ${ }^{33}$. Yeterli ve dengeli beslenme, stres ile baş edebilme, düzenli fiziksel aktivite ve kendini gerçekleştirme, kişilerarası ilişkiler ve bu konularda sorumluluk almak sağlıklı olabilmek için gereklidir $^{34}$. Kendini gerçekleştirme, davranışları yöneten bir güdü yanında ulaşılmaya çalışılan bir gelişim düzeyi olarak da tanımlanmaktadır ${ }^{35}$. Bu bağlamda adölesanların kendini geçekleştirme düzeyleri öz-bakım gücünün gelişimi için önemlidir. Öz-bakım bireysel sağlık sorumluluğu ile ilişkili faktörlerden birisidir. Sağlığın korunabilmesi için adölesanların bireysel sağlık sorumluluk bilinci artırılmalıdır $^{36}$. Öz-bakım gücünü açıklayan değişkenlerden biri sağlık algısıdır (sağlığını çok iyi olarak değerlendirenler) (Tablo 3). Sağlığını iyi olarak değerlendiren adölesanların özbakım gücü puan ortalamaları anlamlı olarak daha yüksek bulunmuştur ${ }^{24,26}$. Adölesan döneminde yaşanan stres bir dizi riskli davranışlarla ilişkilidir. Adölesanlara, stres yaratan durumları tanıyabilme ve stres yönetimi öğretilmelidir. Sağlıklı beslenme konusunda farkındalığın artırılması da, adölesan sağlığı ve performansı için önemlidir. Büyüme ve gelişme nedeni ile artan beslenme ihtiyacı iyi değerlendirilmelidir ${ }^{2}$. Öz-bakım gücünü açıklayan değişkenlerden biri cinsiyettir (kadın olmak) (Tablo 3). Literatürde kızların öz-bakım gücü puan ortalamalarının anlamlı olarak yüksek bulunduğu çalışmalar olduğu gibi24,37, erkeklerin öz-bakım gücü puan ortalamalarının anlamlı olarak daha yüksek bulunduğu ${ }^{26}$ çalışmalar da vardır. Toplumsal roller açısından bu farklıı̆̆ın yaşanan toplumun kültürünün özelliklerinden etkilendiği düşünülmektedir.

\section{SONUÇ ve ÖNERILER}

Adölesanların öz-bakım gücü ve sağlığı geliştirme davranışları arasındaki ilişki ve özbakım gücünü etkileyen faktörleri incelemek amacıyla yapılan bu çalışmada, adölesanların öz-bakım gücü ve sağlığı geliştirme puan ortalamaları orta düzeyde bulunmuştur. Adölesanlar sağlığı geliştirme ölçeğinin kendini gerçekleştirme alt boyutundan en yüksek puanı alırken, en düşük puanı egzersiz alt boyutundan almışlardır. Öz-bakım gücü ile adölesan sağığı geliştirme ölçeği toplam puanı arasında pozitif yönde orta düzeyde ilişki bulunmuştur. Bu çalışmanın sonucunda öz- 
bakım gücünü açıklayan değişkenlerin; kendini geliştirme, sağlık sorumluluğu, sağlık algısı, stres yönetimi, beslenme ve cinsiyet olduğu bulunmuştur.

Okul temelli sağlık programları ile sağlıklı yaşam biçimi davranışlarının adölesanlara kazandırılması gerekmektedir. Öğrencilerin öz-bakım gücünün artırılması için sağlığı geliştirici davranışların kazandırılması gerekmektedir. Adölesanların sağlık ve davranış risklerini ortaya çıkaran veri tabanları oluşturulmalıdır. Geniş örneklemi içeren müdahale temelli kanıta dayalı çalışmaların yapılması önerilmektedir.

Etik Kurul Onayı: Düzce Üniversitesi Girişimsel Olmayan Klinik Araştırmalar Etik Kurulu'ndan alınmıştır (Karar No: 2017/16).

Çıkar Çatışması: Yoktur.

Finansal Destek: Bildirilmemiştir.

Katılımcı Onamı: Çocuklar ve ebeveynlerinden

bilgilendirilmiş onam alınmıştır.

Yazar katkıları:

Araştırma dizaynı: NYŞ, GAÇ

Veri toplama: NYŞ, GAÇ

Literatür araştırması: NYŞ, GAÇ

Makale yazımı: NYŞ, GAÇ

Teşekkür

Çalışmaya katılan adölesanlara ve ebeveynlerine teşekkür ederiz.

Ethics Committee Approval: Approval was obtained from the Non-interventional Clinical Research Ethics Committee of Duzce University (Decision number: 2017/16)

Confict of Interest: Not reported.

Funding: None.

Exhibitor Consent:

Author contributions: Informed consent was obtained from children and their parents

Study design: NYS, GAC

Data collection: NYS, GAC

Literature search: NYS, GAC

Drafting manuscript: NYS, GAC

Acknowledgement: We would like to thank all children and their parents who approved to participate in the study.

\section{KAYNAKLAR}

1. World Health Organisation. Adolescents: health risks and solutions[Internet]. 2018 [Erişim Tarihi 10 Kasım 2018]. Erişim adresi:http://www.who.int/en/newsroom/fact-sheets/detail/adolescents-health-risksand-solutions

2. Yıldırım Şişman N. Adölesan ve Genç Sağlığının Geliştirilmesi. Editör Ayaz Alkaya S. Sağlığın Geliştirilmesi. Ankara: Hedef CS Basın Yayın; 2017. s. 242 - 52.

3. Viner RM, Ozer EM, Denny S, Marmot M, Resnick M, Fatusi A,et al. Adolescence and the social determinants of health. The Lancet. 2012;379(9826):1641-52.

4. Richard AA, Shea K. Delineation of self-care and associated concepts. Journal of Nursing Scholarship. 2011;43(3):255-64.
5. Ryan P, Sawin KJ. The individual and family selfmanagement theory: background and perspectives on context, process, and outcomes. Nursing Outlook. 2009;57(4):217 - 25 .

6. McCormack D. An examination of the self-care concept uncovers a new direction for healthcare reform. Nursing Leadership. 2003;16(4):48 - 65.

7. Webber D, Guo Z, Mann S. Self-care in health: we can define it, but should we also measure it?-. SelfCare. 2013;4(5):101 - 6.

8. Urpí Fernández AM, Zabaleta Del Olmo E, Montes Hidalgo J, Tomás Sábado J, Roldán Merino JF, Lluch Canut M.T. Instruments to assess self-care among healthy children: A systematic review of measurement properties. JAN. 2017;73(12):2832-44.

9. Orem's Self-Care Deficit Nursing Theory [Internet]. [Erişim Tarihi 23 Haziran 2020].Erişim adresi:https://nursing-theory.org/theories-andmodels/orem-self-care-deficit theory.php

10. Pender, N.J. Health Promotion Manual [Internet]. 2011 [Erişim Tarihi 23 Haziran 2020]. Erişimadresi:https://deepblue.lib.umich.edu/bitstrea m/handle/2027.42/85350/HEALTH_PROMOTION_M ANUAL_Rev_5-2011.pdf?sequence=1\&isAllowed $=y$ )

11. Kaya A, Tutar Güven Ş, İşler Dalgıç A. Sağlığı geliştirme modeline göre verilen eğitimin Türkiye'deki hemşirelik araştırmalarında kullanımı. HEAD. 2018;15(3):195201.

12. Pender's Health Promotion Model [Internet]. [Erişim Tarihi 23 Haziran 2020]. Erişim adresi:https://www.nursing-theory.org/theories-andmodels/pender-health-promotion- model.php

13. Ji Y, Xu H, Zhang Y, Liu Q. Heterogeneity of adolescent health risk behaviors in rural western China: A latent class analysis. PloS one. 2018;13(6):e0199286.

14. Persson L, Haraldsson K. Health promotion in swedish schools: Shool managers' views. Health Promotion International. 2017;32(2):231-40.

15. Brooks JE, Moore DD. The Impact of childhood experiences on perceptions of health and wellness in african american young adults. J Afr Am St. 2016;20(2):183-201.

16. Çelikcan G, Özçakır A. Adolesan ile iletişim ve etik sorunlar. Turkiye Klinikleri J Fam Med-Special Topics. 2018;9(6):60-4.

17. Karadamar $M$, Yiğit $R$, Sungur MA. Evaluation of healthy lifestyle behaviours in adolescents. Anatolian Journal of Nursing and Health Sciences. 2014;17(3):131-7.

18. Bulut A, Bulut A, Erçim RE. Sağlık Meslek Lisesi öğrencilerinin sağılılı yaşam biçimi davranışlarının incelenmesi. FNG \& Bilim Tıp Dergisi. 2016;2(2):10512.

19. Özakgül $A A, A s ̧ t ı ~ T A$, Merve A,ve ark. Lise son sınıf öğrencileri sağlıklı yaşam biçimi davranışlarına sahipler mi?. F.N. Hem. Derg. 2016;24(1):16-23. 
20. Kearney BY, Fleischer BJ. Development of an instrument to measure exercise of self-care agency. Res Nurs Health. 1979;2(1):25-34.

21. Nahcivan N. Geçerlik ve güvenirlik çalışması: Öz-bakım gücü ölçeği'nin türkçe'ye uyarlanması. Hemşirelik Bülteni. 1994;7(33):109-19.

22. Chen MY, Wang EK, Yang RJ, Lio YM. Adolescent health promotion scale: Development and psychometric testing.PHN. 2003;20(2):104-10.

23. Temel AB, Başalan İz F, Yıldız $S$, et al. The reliability and validity of adolescent health promotion scale in turkish community. Journal of Current Pediatrics. 2012;9:14 - 22.

24. Ergün SA, Yılmaz E, Dağdeviren Z, Dinçer Ş. Mesleki eğitim ve çıraklık merkezinde eğitim gören ergenlerin öz bakım gücünün incelenmesi. ADÜ Tıp Fakültesi Dergisi 2009;10(3):29-36.

25. Tüfekci FG, Arıkan D. Sağlıklı adölesanların öz-bakım gücü ile anne-babalarının öz-bakım gücünün karşılaştırılması ve sosyo-demografik özelliklerle ilişkisi. Journal of Anatolia Nursing and Health Sciences. 2002;5(1):45-52.

26. Lee SY, Suh SR. Influence of health literacy and selfcare agency on health promotion behavior in nursing students. J Health Info Stat. 2018;43(2):126-33.

27. Sümen $A$, Öncel $S$. Türkiye'de lise öğrencilerinin sağlıklı yaşam biçimi davranışlarını etkileyen faktörler: Sistematik derleme. Eur J Ther. 2017;23:74-82.

28. Dağdeviren Z, Şimşek Z. Şanlıurfa il merkezindeki lise öğrencilerinin sağlığı geliştirme davranışları ve ilişkili faktörler. TAF Prev Med Bull. 2013;12(2):135-42.

29. Karaaslan MM, Çelebioğlu A. Determination of healthy lifestyle behaviors of high school students.JHS. 2018;15(2):1355-61.

30. Bebiş H, Akpunar D, Özdemir S, Kılıç S.Bir ortaöğretim okulundaki adölesanların sağlığı geliştirme davranışlarının incelenmesi. Gülhane Tıp Derg. 2015;57:129-35.

31. Ssewanyana D, Abubakar A, Van Baar A, Mwangala PN, Newton CR.Perspectives on underlying factors for unhealthy diet and sedentary lifestyle of adolescents at a kenyan coastal setting. Front. Public Health. 2018;6:11.

32. Christofaro DGD, De Andrade SM, Mesas AE, Fernandes RA, Junior JCF. Higher screen time is associated with overweight, poor dietary habits and physical inactivity in Brazilian adolescents, mainly among girls. European Journal of Sport Science. 2016;16(4):498-506.

33. Çelik ND, Owen FK. Sağlıklı yaşam biçimi davranışlarının iyilik halini yordayıcılığı. JoSReSS. 2017;3(3):69-88.

34. Owen FK, Çelik ND. Lifelong healthy lifestyle and wellness. Current approaches in psychiatry. 2018;10(4):430 - 43.
35. Ünsar $S$, Akgün Kostak $M$, Kurt $S$, ve ark. Hemşirelerin kendini gerçekleştirme düzeyleri ve etkileyen etmenler. DEUHYO ED. 2011;4(1):2 -6.

36. Avcı YD. Kişisel sağlık sorumluluğu. TAF Prev Med Bull. 2016;15(3):259 - 63.

37. Callaghan D. Basic conditioning factors' influences on adolescents' healthy behaviors, self-efficacy, and selfcare. Issues in Comprehensive Pediatric Nursing. 2006;29(4):191-204. 